\title{
Leitor e Leituras: Considerações sobre Gêneros Textuais e Construção de Sentidos
}

\author{
Sandra Patrícia Ataíde Ferreira ${ }^{1}$ \\ Maria da Graça B. B. Dias \\ Universidade Federal de Pernambuco
}

\begin{abstract}
Resumo
O presente artigo aborda a leitura como uma atividade de construção de sentidos que implica a relação dinâmica entre leitor e texto. Primeiramente, apresenta-se a idéia de que a leitura varia de acordo com o leitor e seus objetivos, concebendo-a como uma atividade afetivo-cognitiva e como prática social. Posteriormente, discutem-se os conceitos de texto, contexto e gênero textual, enfatizando-se a idéia de que o sentido se constitui na relação dialética entre autor/texto/leitor/contexto, sendo esta relação a que favorece uma multiplicidade de sentidos e que, ao mesmo tempo, delimita as possibilidades desta variação, determinando o jogo do implícito e do explícito.

Palavras-chave: Leitura; construção de sentidos; contexto; gênero textual.
\end{abstract}

\section{Reader and Reading: Considerations about Text Types and Meaning Construction}

\begin{abstract}
The present paper emphasizes reading as an activity of meaning construction which implies the dynamic relationship between reader and text. First we present the idea that reading varies accord to the reader and his aims. The reader can concept it as a cognitive- affective activity and a social practice. Later we discuss the text concepts, context and textual types, with the focus in the idea the meaning is constituted in the dialectic relationship among author/text/reader/context. This relationship is which offers many meaning and at the same time, gives limits to the possibilities of the variations and also determines the game of the implicit and the explicit.

Keywords: Reading; meaning construction; context; textual types.
\end{abstract}

Este trabalho tem como objetivo informar ao leitor a concepção de leitura que norteia várias pesquisas realizadas no nosso país como também no exterior (Colomer \& Camps, 1996; Dias, Moraes \& Pessoa 1995; Ferreira, 1998, 2004; Ferreira \& Dias, 2002a; 2002b; Marcuschi, 1985, 1989,1996; Silva, 1996; Smith, 1999; Solé, 1998; Tolchinsky \& Pipkin, 2001; Tolchinsky \& Simó, 2001). Também discorre sobre as concepções de língua, texto, contexto e gênero textual que estão fundamentadas na perspectiva de linguagem como interação e a leitura como um processo que envolve, dentre outras competências, a construção de sentido.

\section{Comunicação escrita}

É no intuito de se comunicar com os outros que o ser humano cria e utiliza variadas formas de linguagem. É através delas que o homem se comunica, tem acesso a informações, expressa e defende pontos de vista, partilha ou constrói visões de mundo, produz conhecimento. Porém, para que a comunicação estabeleça-se é necessário que os interlocutores atribuam sentido ao texto (falado ou escrito), tornando-o compreensível.

Deste modo, a capacidade de compreender apresenta-se como um fator crítico da comunicação humana, pois é através dela, que os significados transmitidos pela cultura tornam-se acessíveis aos indivíduos que compartilham de uma mesma língua, revelando-se aqui, a função de pensamento generalizante da linguagem.

No que tange à comunicação oral, que se caracteriza pelo encontro face a face entre os interlocutores, estes têm à sua disposição pistas

\footnotetext{
${ }^{1}$ Endereço para correspondência: Universidade Federal de Pernambuco, Centro de Filosofia e Ciências Humanas, Departamento de Psicologia, Av. Acadêmico Hélio Ramos, s/n, Cidade Universitária, 50670 901, Recife, PE. Fone: (81) 2710599 (R: 17); Fax: (81) 2711843: E-mail: tandaa@terra.com.br; m-dias@Ig.com.br; mdias@ufpe.br
}

não-verbais, como por exemplo, a prosódia e a gestualidade, que os ajudam a construir o sentido da mensagem. Neste tipo de comunicação, os seus participantes têm a possibilidade do diálogo imediato, que lhes permite intervir no processo de produção textual e a superar os prováveis problemas de compreensão no momento e na situação em que eles ocorrem.

Por outro lado, na comunicação escrita, as pistas paralingüísticas não estão presentes. A possibilidade de diálogo imediato é vetada devido à defasagem de tempo entre a produção e a recepção do texto. Neste tipo de situação, só existem o leitor e o documento escrito, que veicula uma mensagem contendo sentidos a serem desvelados e restaurados pelo leitor quando do ato da leitura. (Silva, 1996) Desta forma, a comunicação escrita pode ser entendida como uma categoria especial de comunicação, que implica a relação dinâmica e ativa entre leitor e texto, na qual o primeiro tem a função de reescrever os sentidos mediados pelo material impresso a partir de seu modelo mental de mundo.

É neste sentido que se diz que a leitura envolve sempre compreensão, compreensão esta que se concretiza na interação entre leitor e texto. Segundo Solé (1998), esta concepção de leitura traz embutida em si três grandes conseqüências: 1) a idéia de sujeito ativo, como já foi explicitada; 2) a idéia de que a leitura é sempre guiada pelos objetivos do leitor; e uma outra idéia ligada estritamente a esta última; e, 3) a de que a interpretação depende destes objetivos, havendo tantas interpretações quantos objetivos existirem. Portanto, apesar do conteúdo do texto ser invariável, há uma variabilidade de interpretação de leitura de acordo com o leitor, seus interesses, conhecimentos e objetivos, fazendo com que a compreensão não seja encarada como uma questão de tudo ou nada ou como uma atividade de precisão, com regras exatas.

Porém, como a leitura é o resultado da relação entre leitor e texto, não se pode concebê-la, por outro lado, como uma atividade de 
vale tudo (Marcuschi, 1996) ou como uma caixinha de surpresas (Marcuschi, sd), já que o autor tem um projeto de dizer (Koch, 2002) e utiliza estratégias de organização textual que sinaliza para o leitor as possibilidades de construção de sentidos. Sentidos que serão construídos a partir da estrutura lingüística do texto, de suas sinalizações e do contexto que o leitor é capaz de mobilizar tendo em vista seus conhecimentos e experiências prévios. Isto implica dizer que, as intenções e objetivos do autor revelam-se na estrutura lingüística do texto e que esta delimita (sem limitar) as possibilidades de construção de sentidos por parte do leitor. São as pistas lingüísticas que favorecem, neste último, a ativação do conhecimento necessário para a reconstrução do mundo textual criado pelo autor.

Então, pode-se dizer que, existem limites para a compreensão textual e que estes são estabelecidos na própria relação entre autor e leitor, mediada pelo texto. Limites estes que se rompem quando da inexistência de compartilhamento de conhecimentos entre os interlocutores de uma situação comunicativa, gerando má compreensão ou não compreensão devido à quebra da cooperação entre eles. O produtor do texto tem intenções e deseja que o leitor produza os sentidos por ele desejado. O leitor sabe que o autor tem algo a dizer e se esforça para compreendê-lo. Quando o leitor não dispõe de conhecimentos suficientes para reconstruir os sentidos construídos pelo autor do texto, o processo de construção de sentidos ou não se efetiva ou não é bem-sucedido.

Diante desta perspectiva, entende-se que ler é compreender e que compreender é um processo de construção de sentidos que pressupõe uma atividade de seleção, reorganização e reconstrução (Dell'Isola, 2001; Silva, 1996; Smith, 1999; Solé, 1998). Para compreender um texto, o leitor precisa ir além do texto, indo além do que está colocado explicitamente: ele precisa ligar as idéias dentro do texto e ativar seu conhecimento geral para suportar a sua compreensão. Ou seja, para compreender um texto, o leitor precisa fazer inferências que podem ser elaboradas tanto a partir das relações entre os elementos do próprio texto, como através das relações entre estes e seu conhecimento prévio (conhecimentos lingüísticos, enciclopédicos, de mundo).

Assim, quando interage com o texto, o leitor tanto capta a informação nele veiculada, como transmite a ele toda a carga de sua experiência anterior, transformando-o e transformando-se; compreendendo-o e compreendendo-se. Como diz Freire (1994, p. 20), ... a leitura da palavra não é apenas precedida pela leitura do mundo, mas por uma certa forma de 'escrevê-lo' ou de 'reescrevê-lo', quer dizer, de transformá-lo através de nossa prática consciente.

Portanto, além de uma atividade cognitiva, a leitura é também uma atividade social, situada, construtiva, dialógica e interativa que envolve a participação ativa do leitor, que se apóia em suas experiências passadas, em seus objetivos de leitura, em seus conhecimentos e idéias prévias, e no texto e contexto para gerar sentidos que se constroem nas várias transações e negociações entre estes, e os seus conhecimentos.

Acredita-se que nem o texto nem o leitor mostram-se, por si só, como condição suficiente para garantir a construção de sentidos veiculados pelo texto. Pelo contrário, defende-se que ambos são necessários e que a reelaboração do sentido textual é influenciada sobremaneira pela história cognitiva e afetiva do leitor. Incluindo-se aqui, a sua motivação e o comprometimento com a leitura, pois para atuar com disponibilidade frente a um texto, o leitor precisa encontrar sentido, deve saber porque lê e se sentir motivado para esta atividade.

Além disso, a leitura deve ser entendida como uma atividade que implica a elaboração de representações mentais (Oakhill \& Garnham, 1988), uma vez que a compreensão dela extraída não se apresenta como uma cópia real do conteúdo lido, sofrendo, do contrário, interferência da totalidade sócio-afetivo-político-cognitiva que é o leitor: suas experiências atuais e passadas, seus conhecimentos geral e de mundo, suas perspectivas, seus interesses, seus objetivos, suas crenças e valores, suas capacidades e habilidades. Ao mesmo tempo em que, o texto intervém sobre o leitor, modificando o seu modo de perceber e transitar no mundo, conferindo-lhe autonomia.

Enquanto atividade interativa e construtiva que é, a leitura não pode ser analisada nem compreendida de forma descontextualizada e despersonalizada, negando-se a história do sujeito enquanto ser diferenciado dos seus pares. O que, por sua vez, desvela a relação entre leitura e subjetividade; e, todavia, entre leitura e construção de sentidos (Barone, 1993), que é entendido aqui como uma interpretação individual, pessoal e única de informações ou linguagens que são acessíveis a um grupo de indivíduos que compartilha de significados que são públicos. O leitor precisa compartilhar dos sentidos construídos pelo autor, mas precisa ser capaz de construir os seus próprios sentidos, que serão constituídos e orientados pelas suas vivências, experiências e conhecimentos, os quais se diferenciam tanto em conteúdo como em elaboração dos demais leitores e do próprio autor.

Assim, concebe-se a leitura como um ato individual e como uma prática social (Lerner, 2002) possibilitadora de transformação do eu, do outro e do mundo. Como ato individual, mostra-se essencialmente como um processo cognitivo, que exige além da decodificação, memorização e processamento estratégico, o ato de internalização e de reelaboração do contexto textual e imediato. Além disso, a leitura enquanto ato individual deve ser compreendida como uma competência em torno da qual se organizam as demais competências e habilidades cognitivas, sendo, portanto, tomada como uma arquicompetência (Murrie, 1999) que pode retardar, interromper ou possibilitar o amplo desenvolvimento de outras competências ou habilidades em conseqüência de seu próprio desenvolvimento pleno ou precário.

Como prática social, deve ser vista como um instrumento de aquisição dos conhecimentos construídos pela humanidade e como meio de repensar a realidade e de reestruturá-la a partir da crítica e do questionamento sobre esta mesma realidade. Deve ser tomada como uma atividade cotidiana que cumpre com os mais variados propósitos sócio-comunicativos: ler para resolver problemas práticos (fazer uma comida, saber sobre o funcionamento de um instrumento...); ler para se informar sobre um tema de interesse; ler para escrever; ler para buscar informações específicas (a definição de um conceito, o endereço de uma empresa, o significado de uma palavra...); ler para compartilhar com outros leitores contos ou poesias, por exemplo. 
Portanto, a dimensão social da leitura parece retratar a relação estreita entre o desenvolvimento da atividade de leitura e o desenvolvimento de outras competências e habilidades cognitivas, uma vez que para intervir e modificar o mundo faz-se necessário ao indivíduo abstraí-lo, analisá-lo, compreendê-lo, interpretá-lo, inferilo, sintetizá-lo através de uma ação consciente que se organiza a partir da aquisição de conhecimentos sistematizados. Ao mesmo tempo em que, para compreender mais amplamente este mundo, o indivíduo precisa estar apto a lê-lo através das várias linguagens pelas quais ele se expressa: a matemática, a artística, a biológica, a tecnológica, a científica. Leituras estas que demandam o domínio de determinadas competências.

Segundo Perrenoud (1999, p. 7), existem múltiplos significados para a noção de competência. Para ele, no entanto, competência é a ... capacidade de atuar eficarmente sobre uma determinada situação, apoiada em conhecimentos, mas sem limitar-se a eles. De acordo com esta noção, para que o indivíduo possa enfrentar uma situação, faz-se necessário que o mesmo mobilize, além do conhecimento, vários outros recursos cognitivos complementares, como acontece, por exemplo, no ato de leitura. Portanto, não basta ter o conhecimento necessário e adequado para lidar com as situações, éimprescindível que o indivíduo saiba mobilizá-lo e utilizá-lo de maneira apropriada para que ele possa ser usado em função ou em benefício dos processos cognitivos ou operações mentais exigidas por tais situações, que se repetem e/ou se renovam ao longo da vida e que possibilitam a construção de novas competências.

A leitura possibilita uma reorganização do conhecimento prévio com outros novos conhecimentos trazidos pela leitura recente. O conhecimento é reorganizado e torna-se mais completo e complexo, permitindo relações com novos conceitos, as quais favorecem a mudança e a aprendizagem. Mas para tal, é necessário que o leitor vá fundo na leitura, desentranhando a informação, discernindo o essencial do acessório e estabelecendo o maior número de relações entre as informações novas e antigas e isto, por sua vez, exige a aprendizagem de estratégias de leitura, que devem ser ensinadas e explicitadas no processo de ensino.

Portanto, como ressaltam Solé (1998), Carvajal e García (2000), e Lerner (2002), a leitura não pode ser concebida, apenas, como uma ferramenta ou um instrumento para outras aprendizagens, mas também como um objeto de conhecimento, que como tal exige e possibilita a emergência de formas de raciocínio e modos de pensar também específicos, que são gerados a partir da interação do sujeito cognoscitivo com este objeto de conhecimento; e que são determinados tanto pela natureza deste objeto, como pelo contexto e pelas características do indivíduo-leitor.

Assim, como objeto de conhecimento que é, a leitura precisa ser ensinada e aprendida: o sujeito-leitor precisa aprender a decodificar e a usar as estratégias que levam à compreensão e ao seu controle; ao mesmo tempo em que, os procedimentos ou estratégias de leitura precisam ser explicitados e demonstrados ao leitor-iniciante por parte daquele que orienta a sua aprendizagem, como, aliás, é comum acontecer no processo de ensino de outras áreas do conhecimento. No entanto, como aponta Solé (1998), a instrução da leitura ainda limita-se, de modo geral, à decodificação, havendo muito mais avaliação do que ensino da leitura em sala de aula, ficando o seu tratamento, enquanto objeto de conhecimento, aquém do que se poderia desejar.

\section{Gênero textual e produção de sentidos}

São vários os textos que circulam no mundo letrado. Textos que são lidos diferentemente de acordo com a época, condições e história do leitor. Leitor este que, por sua vez, orienta a sua compreensão de acordo com a organização assumida pelo texto. Mas o que é um texto? Quais as categorias assumidas para a sua definição?

De acordo com Koch $(2000,2002)$, o conceito de texto depende das concepções de linguagem, língua e sujeito que são assumidas. Deste modo, ela apresenta três conceitos de textos relacionados às três principais concepções de linguagem, língua e sujeito desenvolvidas ao longo da história.

À concepção de língua e linguagem como representação (espelho) do mundo e do pensamento, subjaz uma noção de sujeito individual, de consciência, dono absoluto de suas ações e de seu dizer, que constrói uma representação mental que deseja ser capturada pelo interlocutor tal como foi realizada. Nesta perspectiva, o texto é concebido como um produto (lógico) do pensamento do autor, que deve ser capturado, fotografado passivamente pelo leitor. O texto, neste caso, é tomado como uma estrutura fechada, responsável pela transmissão de um único sentido que exerce uma influência unívoca: texto interferindo sobre o leitor.

$\mathrm{Na}$ concepção de língua e linguagem como estrutura, como código e como instrumento de comunicação, o sujeito é visto como assujeitado, inconsciente e determinado pelo sistema. Sujeito que não sabe o que diz porque não sabe quem é. Sujeito repetidor, que fala o que a ideologia, a instrução deseja que fale, apesar de ter a ilusão que fala por si. De acordo com esta noção de língua e sujeito, o texto é tomado como um produto de codificação de um emissor a ser decodificado pelo leitor. $\mathrm{O}$ texto é visto como totalmente explicitado pela codificação, sendo o leitor um indivíduo totalmente passivo, já que seu papel limitase a decodificar a mensagem, o escrito (ou falado) sem se preocupar com o não dito, com o não explicitado pelo código.

Já na concepção de língua e linguagem como forma de ação ou interação e de sujeito como entidade psicossocial, que se constitui na sua relação com o outro, o texto é concebido como o próprio lugar da interação. Texto que se constrói na interação entre interlocutores e que carrega toda uma gama de implícitos, revelados pelo conhecimento do contexto sociocognitivo dos interlocutores. Interlocutores estes vistos como sujeitos ativos, que constroem e são construídos pelo texto.

De acordo com esta última concepção, que é assumida neste trabalho, o texto é tomado como um sistema de significado aberto, que dá margem a uma multiplicidade de sentidos. Sentidos construídos no momento da interação texto/leitor. Leitor que tem uma história (de vida e de leitura) e que traz esta história para a relação que mantém com o produtor do texto, retomando-a e reconstruindo-a nesta interação recíproca. $\mathrm{O}$ texto é um tecido tramado a cada contato 
com o leitor, em cada momento histórico e contexto sociocultural, sendo as suas teias constituídas de implícitos que surgem do explícito e do revelado (Dell'Isola, 2001).

Neste caso, pode-se dizer que o texto mantém relação com o contexto e com outros textos. Ele se constitui na interação e não acaba em si mesmo, recebendo a influência da história de leitura do autor e do leitor do texto. (Costa Val, 1999; Koch \& Travaglia, 2001; Koch, 2002) Ao escrever, o autor remete-se aos vários textos que leu, selecionando, de forma não aleatória, o que parece pertinente para a produção atual. Quando lê o texto, o leitor ativa o seu conhecimento de outros textos, também de forma seletiva, para fazer sentido do que lê.

Como diz Orlandi (1996), o contexto é constitutivo do sentido, já que a variação nas condições de produção afeta a construção de sentidos que emergem a partir da interação entre interlocutores. Então, ler um texto em busca de informações para responder questões pontuais, não possibilita a mesma produção de sentidos que um contexto de leitura em que o leitor busca relações e implicações subjacentes às informações deste mesmo texto.

Como argumenta Koch (2002), fundamentada na Lingüística Textual, o contexto não abrange apenas o co-texto ou entorno verbal, mas também a situação de interação imediata, a situação mediata (entorno sociopolítico e cultural) e o contexto sociocognitivo dos interlocutores. Englobando este último, todos os outros já citados e que fazem parte da memória dos participantes e que necessitam ser mobilizados durante a troca lingüística.

Percebe-se desta forma que, o contexto não diz respeito a uma "situação real", mas a um conjunto de suposições que faz parte do contexto cognitivo do leitor e do autor e que é ativado da memória a partir da interação que se estabelece entre eles. A mobilização do que é relevante na memória vai depender, então, do co-texto e de suas relações com o contexto cognitivo dos indivíduos.

Relações estas que possibilitam uma variabilidade de sentidos, mas que, ao mesmo tempo, delimitam as possibilidades desta variação. Isto porque o contexto cognitivo vai ser ativado a partir das relações com o co-texto, ou seja, a partir do entorno verbal. São estas relações também que vão determinar o jogo do implícito e do explícito. É a ativação ou não de um contexto cognitivo que vai favorecer ou não a explicitude de uma idéia ou proposição de um texto, gerando, assim, sentidos diferenciados de acordo com diferentes leituras e leitores. Isto sugere que, além de ser determinada pelos conhecimentos e experiências do leitor, a leitura também é determinada pela superestrutura textual. Superestrutura esta que exige diferentes tipos de estratégias e que determina a natureza da relação que este leitor mantém com o texto. A posição de um leitor frente a uma lista telefônica não é de natureza similar a que ele assume frente a um texto narrativo, por exemplo. A superestrutura textual orienta a leitura que o indivíduo faz do texto.

Todo texto possui uma organização ou estruturação (superestrutura) mais ou menos estável, que constitui o gênero textual. A denominação dos gêneros é estabelecida em critérios heterogêneos, havendo variação das categorias em função do uso que se faz delas. Essa categorização pode ser realizada a partir do conteúdo, do modo de organização ou do tipo de circulação do texto em uma sociedade (Koch, 2002; Maingueneau, 2001).

O gênero é usado de acordo com as necessidades e objetivos do autor (locutor). Esta escolha é guiada pelo conjunto de gêneros já existentes e elaborados por gerações anteriores. Contudo, isto não significa dizer que os gêneros sejam rígidos e que o discurso do autor deve ser moldado de acordo com essas formas preexistentes. Como diz Orlandi (1996, p. 153) ... o produto se repõe como processo. O produto elaborado pela cultura toma-se processo quando da interação entre interlocutores reais ou virtuais.

Isto, por sua vez, tem impacto sobre a ativação do contexto cognitivo do leitor e, conseqüentemente, sobre a sua compreensão do texto. O leitor, em seu encontro com o texto, precisa mobilizar seus conhecimentos sobre os gêneros textuais para ser capaz de negociar sentidos quando em interação com o autor.

É o contato com os vários textos que circulam no social que permite o desenvolvimento da capacidade metatextual por parte do indivíduo, possibilitando-lhe pensar no texto como objeto de conhecimento e verificar as características peculiares deste objeto. Ao mesmo tempo em que, é esta capacidade que lhe garante a identificação e diferenciação dos gêneros textuais.

Também é esta mesma capacidade que permite ao leitor identificar se em um texto há predominância de seqüências textuais de caráter narrativo, descritivo, expositivo e/ou argumentativo. Isto porque os gêneros não são puros, mas hỉbridos. (Koch, 2000; Orlandi, 1996) Um texto narrativo, por exemplo, pode conter em si seqüências descritivas, dialógicas e argumentativas, mas sem perder as características predominantemente narrativas, como é o caso da seqüencialidade no tempo e o problema ou conflito.

Segundo Bronckart (1999), o plano geral do texto ou infraestrutura, como denomina, é determinado pelos tipos de discurso que ele assim classifica: a narração e o relatado interativo, na ordem do NARRAR; e o discurso teórico, o interativo e o tipo misto teóricointerativo, na ordem do EXPOR. Discursos estes que se articulam diferentemente, gerando gêneros textuais em número ilimitado.

Partindo de uma perspectiva sociodiscursiva, este autor defende que todo texto é considerado um exemplar de gênero, necessariamente composto de um ou vários tipos de discurso, que se planifica, eventualmente, em uma ou várias seqüências convencionais. Decorrendo disto o fato de os gêneros não poderem ser diretamente definidos e classificados em função das características lingüísticas neles observáveis.

Os gêneros, conforme Bronckart (1999), podem ser classificados indiretamente, tomando-se como critério de análise as espécies de ação de linguagem que semiotizam. Além disso, ele defende que esta classificação pode ocorrer tomando-se as modalidades recorrentes de composição dos tipos de discurso e dos tipos de seqüências que neles são observáveis. Também entende que as seqüências são modelos abstratos que produtores e receptores de textos dispõem e que podem ser definidas, ao mesmo tempo, pela natureza e articulação entre as macroproposições que se organizam em estruturas autônomas.

Portanto, partindo desta perspectiva, a composição dos textos varia de acordo com a variedade de seqüências e de suas modalidades 
de articulação. Afinal, uma seqüência pode ser formada de todas as macroproposições que a compõem ou apenas de algumas delas. Deste modo, o todo muda, já que os elementos não são os mesmos, assim como, não é a mesma a articulação que se estabelece entre eles.

Bronckart (1999), ao discutir a organização textual, destaca tanto as seqüências como outras formas de planificação de textos. Quanto às primeiras, ele apresenta as seguintes: a seqüência narrativa, a descritiva, a injuntiva, a argumentativa, a explicativa e a dialogal. No que se refere às outras formas de planificação, ressalta o script, na ordem do NARRAR, e as esquematizações, na ordem do EXPOR.

No caso da seqüência narrativa, esta é sustentada, especialmente, por um processo de intriga e não, simplesmente, pela organização dos acontecimentos em um eixo sucessivo. Caracteriza-se por um todo acional: um estado de equilibrio é perdido por um estado de tensão que desencadeia transformaçẽes, que tendem a um novo estado de equilibrio. Esse todo acional também é produtor de causalidade: a ordem cronológica, a qual sobrepõe uma ordem interpretativa, permite atribuir razões aos encadeamentos dos acontecimentos, na história.

A seqüência narrativa é assumida como se constituindo de cinco fases, que se sucedem: a de atuação inicial (estado considerado equilibrado), a de complicação (introdução de uma perturbação), a de ações (acontecimentos desencadeados pela perturbação), a de resolução (introdução de acontecimentos que levam à efetivação da redução da tensão), e a de situação final (explica o novo estado de equilíbrio conquistado pela resolução do conflito).

Acrescenta-se a estas mais duas fases que, segundo Bronckart (1999), são menos restritas porque dependem mais diretamente do posicionamento do narrador em relação à história narrada: a fase da avaliação (comentário sobre o desenrolar da história) e a fase de moral (explica a significação global da história). Essas fases podem variar de acordo com o texto, podendo apresentar um número limitado das mesmas: situação inicial, complicação e resolução, apenas.

A seqüência descritiva compõe-se de fases que se organizam e se encaixam de maneira hierárquica ou vertical. Compreende três fases principais: a ancoragem (em que o tema da descrição é assinalado de forma nominal ou tema-título), que pode aparecer no início da seqüência (ancoragem propriamente dita), no seu final (afetação) ou no curso da mesma, sendo posteriormente retomada (reformulação). A fase de aspectualização (enumeração dos diversos aspectos do tema) e a fase de relacionamento (os elementos descritos são relacionados a outros, a partir de operações de caráter comparativo ou metafórico).

Existem também os segmentos que são chamados de injuntivos, instrumentais ou procedimentais que são observados nas receitas de cozinha e nas instruções de uso, por exemplo. Eles apresentam as mesmas fases das seqüências descritivas, mas diferem em seus objetivos. No caso dos segmentos injuntivos, o autor pretende que o destinatário aja de determinado modo e em determinada direção. Isto recai sobre as propriedades da seqüência, como é, por exemplo, a presença de formas verbais no imperativo no caso das receitas de cozinha.

Como acontece com a seqüência narrativa, a seqüência descritiva constitui um modelo abstrato. Pode-se realizar de maneira rudimentar (tema-título e enumeração de suas partes) ou de maneira mais complexa, havendo o surgimento de subtemas a partir da caracterização das propriedades dos temas, assim como, de subsubtemas a partir dessas propriedades.

Quanto à seqüência argumentativa, pensada não em termos das leis da lógica matemática, mas em termos dos processos de lógica natural que se desenvolvem nos textos existentes nas línguas naturais; esta se realiza quando o objeto de discurso mostra-se problemático para o destinatário, levando o autor ou produtor a lançar mão dela. Ela se apresenta como uma sucessão de quatro fases: a fase de premissas (que se propõe uma constatação de partida); a fase de apresentação de argumentos (elementos que orientam para uma conclusão provável e que se apóiam em lugares comuns, regras gerais, exemplos); a fase de apresentação de contra-argumentos (apresenta uma restrição à orientação argumentativa, podendo ser refutada ou apoiada por lugares comuns, exemplos) e; a fase de conclusão (integra os efeitos dos argumentos e contra-argumentos).

Do mesmo modo que ocorre com as outras seqüências já apresentadas, a seqüência argumentativa pode apresentar-se de modo simplificado (premissa à conclusão, por exemplo) ou de maneira mais complexa, apresentando todas as fases que a compõem.

No caso da seqüência explicativa, que surge a partir de um objeto de discurso contestável, esta se apresenta, em geral, na forma de uma seqüência bastante simples. Ela compreende quatro fases: a fase da constatação inicial (introduz um acontecimento não contestável); a fase de problematização (explicita uma questão da ordem do porque ou como); a fase de resolução (apresentação de informações suplementares capazes de responder as questões colocadas) e; a fase de conclusão-avaliação (formula ou completa a constatação inicial).

As seqüências dialogais, por sua vez, concretizam-se, apenas, nos segmentos de discursos dialogados. Segmentos estes estruturados em turnos de fala. Os discursos interativos podem ser primários ou secundários. Os primários são diretamente assumidos pelos agentes que o produzem em uma interação verbal, como é o caso de uma conversa, por exemplo. Já os secundários, são aqueles que dizem respeito ao diálogo que ocorre entre personagens que aparecem quando de um discurso principal. Isto acontece, por exemplo, quando em uma conversa, um dos locutores traz à cena o diálogo de duas pessoas a quem se refere no seu discurso atual.

Só existe diálogo quando os interlocutores estão engajados em uma conversação, em que seus enunciados determinam-se mutuamente, sendo o texto constituído na interação. Esta, segundo Bronckart (1999), apresenta-se como uma condição restritiva para a definição de diálogo.

A seqüência dialogal mostra-se organizada em três níveis encaixados. O nível supraordenado, que se apresenta em três fases: a de abertura (contato inicial entre os interlocutores), a transacional (em que o conteúdo temático é co-construído) e a de encerramento (que põe fim à interação). Cada qual apresentando uma troca.

Em um segundo nível, cada fase apresentada no primeiro nível pode ter uma ou mais trocas, dependendo também do número de interlocutores. A troca é composta de intervenções, isto é, de turnos de fala. Já no terceiro nível, cada intervenção pode ser decomposta 
em enunciados que realizam atos de fala determinados (pedido, afirmação...).

Como as demais seqüências, as explicativas e dialogais sofrem variações, podendo-se realizar de maneira simples ou complexa. No caso das seqüências explicativas, estas podem apresentar as quatro fases ou não. Já as dialogais, elas podem variar de acordo com a complexidade e amplitude dos encaixes hierárquicos.

Sobre as outras formas de planificação, Bronckart (1999) destaca, como já foi dito acima, o script, na ordem do NARRAR, e que diz respeito à organização dos acontecimentos e/ou ações na história em uma ordem cronológica, mas sem apresentar uma tensão, que é própria da seqüência narrativa. Segundo este autor, este tipo de planificação é encontrado em numerosos segmentos de texto deste tipo de ordem, sendo considerado como grau zero de planificação.

Quanto à ordem do EXPOR, este autor salienta as esquematizações, que se apresentam em segmentos de texto como os informativos e os expositivos, nos quais o objeto de discurso não se mostra nem problemático (seqüência argumentativa) nem contestável (seqüência explicativa), mas neutro ou neutralizado. As esquematizações podem fazer parte, por exemplo, dos domínios da definição, da enumeração, do enunciado de regras e da cadeia causal. Podem ser consideradas como o grau zero da planificação da ordem do EXPOR.

No que concerne às seqüências, faz-se necessário ressaltar, especialmente, o estatuto que Bronckart (1999) lhes atribui. Para este autor, estes protótipos não são modelos cognitivos preexistentes, que se originam de uma competência textual biologicamente fundada. Eles se originam da experiência do intertexto, em suas dimensões prática e histórica, podendo modificar-se permanentemente.

As seqüências constituem-se de uma reestruturação dos conteúdos temáticos existentes na memória do produtor do texto e que se apresentam em forma de macroestruturas. Reestruturação que é motivada pelas representações que o produtor tem de seus destinatários, assim como, do efeito que deseja produzir nestes. No que se refere à leitura, a reestruturação das macroestruturas depende de como o texto é organizado, do conhecimento do leitor sobre o autor (suas expectativas) e do efeito que o produtor causa no mesmo.

Deste modo, Bronckart (1999) atribui um estatuto fundamentalmente dialógico às seqüências. Ele considera que o empréstimo de uma dessas seqüências passa pelas decisões do produtor/autor, as quais são orientadas pelas representações que este faz do seu destinatário e pelos seus objetivos. Portanto, essas decisões não são aleatórias. Elas são tomadas na intertextualidade. Esta tomada de decisão passa pela relação com outros textos: textos com os quais o autor já teve contato e textos com os quais ele pensa que seu destinatário já teve contato. Intertextualidade esta que lhe ajuda a organizar o texto de modo que lhe permite dizer o que pretende dizer e a ser compreendido.

Outro ponto importante a destacar sobre a idéia de organização textual ou plano de texto defendida pelo autor, diz respeito à variabilidade desta organização a partir da relação entre tipos de discurso, seqüências e formas de planificação, que dá ao texto um caráter de flexibilidade. Texto que é organizado tomando-se como base não só os objetivos do autor, mas a posição ou lugar atribuído ao leitor/ouvinte. Se o texto só se constitui como tal na sua relação com o leitor/ouvinte este precisa ser organizado de modo a ser por ele compreendido. Daí a importância da dimensão dialógica nesta constituição.

\section{Considerações Finais}

É através da experiência que o indivíduo é levado a descobrir os mistérios do texto e da leitura, já que a mesma ajuda-o a compreender o poder facilitador que a linguagem tem, permitindo, conseqüentemente, o entendimento de seu uso. Compreensão que, como se sabe, requer o mergulho em situação de busca e geração de sentidos. O que, por sua vez, permite o estabelecimento de relações entre as coisas do mundo, possibilitando a sua explicação a partir da explicitude do implícito, que ocorre tomando-se como base o já conhecido.

Compartilhando com as idéias difundidas nos Parâmetros Curriculares Nacionais de Língua Portuguesa (Brasil, 1997), defendese que é necessário que se "aprenda a ler, lendo" e que se ensine a ler oferecendo práticas de leitura que privilegiem a reflexão e que promovam o desenvolvimento de estratégias de leitura semelhantes àquelas utilizadas pelo leitor proficiente, objetivando-se, acima de tudo, a construção de sentidos.

Deste modo, entende-se a leitura como uma atividade social e interativa, voltada à construção de sentidos, que são gerados na interlocução leitor-texto-autor através do intercruzamento das várias informações no texto e entre elas e os conhecimentos prévios do leitor. Conhecimentos estes tomados como imprescindíveis para o processo de compreensão de leitura. (Foucambert, 1994, 1997; Marcuschi, 1985, 1989, sd; Silva, 1996; Smith, 1999) Além disso, a leitura deve ser concebida como uma atividade que precisa ser ensinada e aprendida a partir de estratégias que devem ser explicitadas ao leitor-iniciante por um adulto-leitor competente. (Gallart, 2001a, 2001b; Nemirovsky, 2001; Solé, 1998; Tolchinsky \& Simó, 2001)

\section{Referências}

Barone, L. M. C. (1993). De ler o desejo ao desejo de ler. Petrópolis, RJ: Vozes. Brasil - Ministério da Educação e do Desporto (1997). Parâmetros Curriculares Nacionais - Língua Portuguesa. Brasília: Secretaria de Ensino Fundamental.

Bronckart, J. P. (1999). Atividade de linguagem, textos e discursos: Por um interacionismo sócio-discursivo (A. R. Machado \& P. Cunha, Trad.) (pp.217-257). São Paulo: EDUC. (Original publicado em 1997)

Carvajal, P. F. \& García, J. R. (2000). Ensinar ou aprender a ler e escrever? Em F. Carvajal Pérez \& J. R. García (Orgs.), Ensinar ou aprender a ler e a escrever? Aspectos teóricos do processo de construção significativa, funcional e compartilbada do código escrito (pp.). Porto Alegre: ArtMed.

Colomer, T. \& Camps, A. (1996). Enseñar a leer, enseñar a comprender. Madrid: Celeste/MEC.

Costa Val, M. G. (1999). Redação e textualidade (2 ed.). São Paulo: Martins Fontes.

Dell'Isola, R. L. P. (2001). Leitura: Inferencias e contexto sociocultural $\left(2^{\mathrm{a}}\right.$ ed.; Série educador em formação). Belo Horizonte, MG: Formato.

Dias, M. G. B. B., Morais, E. P. \& Pessoa, M. C. (1995). Dificuldade na compreensão de textos: Uma tentativa de remediação. Arquivos Brasileiros de Psicologia, 47, $13-22$. 
Ferreira, S. P. A. (1998). Dificuldades de compreensão de leitura: Análise comparativa da eficácia das estratégias de tomar notas e da imagem mental. Dissertação de Mestrado não-publicada, Pós-graduação em Psicologia, Universidade Federal de Pernambuco. Recife, PE.

Ferreira, S. P. A. (2004). As luzes e as sombras das condicões de leitura na escola: Um olhar sobre dois mundos. Tese de Doutorado não-publicada, Pós-graduação em Psicologia, Universidade Federal de Pernambuco. Recife, PE.

Ferreira, S. P. A \& Dias, M. B. B. (2002a). Dificuldades de compreensão: Estratégias de tomar notas e da imagem mental. Psicologia: Teoria e Pesquisa, 18, 51-62.

Ferreira, S. P. A \& Dias, M. B. B. (2002b). A escola e o ensino da leitura. Psicologia em Estudo, 7, 39-49.

Foucambert, J. (1994). A leitura em questão (B. C. Magno, Trad.). Porto Alegre: ArtMed. (Original publicado em 1989)

Foucambert. J. (1997). A crianç, o professor e a leitura (M. Cohen \& C. M. Rosa, Trads.). Porto Alegre: ArtMed. (Original publicado em 1994)

Freire, P. (1994). A importância do ato de ler $\left(29^{\mathrm{a}}\right.$ ed.; Coleção Questões da Nossa Época: Vol. 13). São Paulo: Cortez.

Gallart, I. S. (2001a). Leer, lectura, comprensión: ¿Hemos hablado siempre de lo mismo? Claves para La Innovación Educativa, 10, 15-33.

Gallart, I. S. (2001b). ¿Lectura en educación infantil? ¡Sí gracias! Claves para La Innovación Educativa, 10, 69-78.

Koch, I. V. (2000). A inter-ação pela linguagem ( $5^{a}$ ed.). São Paulo: Contexto.

Koch, I. V. \& Travaglia, L. C. (2001). A coerência textual (13a ed.). São Paulo: Contexto.

Koch, I. V. (2002). Desvendando os segredos do texto. São Paulo: Cortez.

Lerner, D. (2002). Ler e escrever na escola: O real, o possivivel e o necessário (E. Rosa, Trad.). Porto Alegre: ArtMed. (Original publicado em 2001)

Maingueneau, D. (2001). Análise de textos de comunicação (C. P. Souza-e-Silva \& D. Rocha, Trads.). São Paulo: Cortez. (Original publicado em 1998)

Marcuschi, L. A. (1985). Leitura como processo inferencial num universo cultural cognitivo. Leitura: Teoria e Prática, 4, 1-14.
Marcuschi, L. A. (1989). O processo inferencial na compreensão de textos. Relatório Final apresentado ao CNPq. Programa de Pós-graduação em Letras e Lingüística. Centro de artes e comunicação. UFPE, Recife.

Marcuschi, L. A. (1996). Exercícios de compreensão ou copiação nos manuais de ensino de língua? Em Aberto, 16, 69, 64-82.

Marcuschi, L. A. (sd). Compreensão textual como trabalho criativo. (Manuscrito nãopublicado)

Murrie, Z. F. (1999). A área linguagens e suas tecnologias no ENEM. I Seminário do Exame Nacional do Ensino Médio-Textos de aprofundamento dos eixos teóricos, 33-39, INEP, MEC.

Nemirovsky, M. (2001). Evolución de las preguntas, evolución del aprendizado. Textos, 27, 53-64.

Oakhill, J., \& Garnham, A. (1988). Becoming a skilled reader. Oxford: Blackwell.

Orlandi, E. P. (1996). A linguagem e seu funcionamento: as formas do discurso (4a ed.). Campinas, SP: Pontes.

Perrenoud, P. (1999). Construir as competências desde a escola. Porto Alegre: ArtMed.

Silva, E. T. (1996). O ato de ler: fundamentos psicológicos para uma nova pedagogia da leitura ( $7^{\mathrm{a}}$ ed.). São Paulo: Cortez.

Smith, F. (1999). Leitura Significativa ( $3^{\mathrm{a}}$ ed.). Porto Alegre: ArtMed.

Solé, I. (1998). Estratégias de leitura (C. Schilling, Trad.). Porto Alegre: ArtMed. (Original publicado em 1996)

Tolchinsky, L. \& Pipkin, M. (2001). Seis lectores en busca de un texto. Clavespard La Innovación Educativa, 10, 99-109.

Tolchinsky, L. \& Simó, R. (2001). Escribiry leer a través del curriculum. Barcelona, ICE. Universidad de Barcelona y Horsori Editorial.

Recebido: 30/04/2004 Aceite final: 22/10/2004

Sobre as autoras

Sandra Patrícia Ataíde Ferreira é Professora do Departamento de Psicologia e Orientação Educacionais, Centro de Educação da Universidade Federal de Pernambuco (UFPE). É Psicóloga, Mestre e Doutora em Psicologia Cognitiva pela UFPE.

Maria da Graça Bompastor Borges Dias é Professora do Programa de Pós-graduação de Psicologia da UFPE é Psicóloga, Mestre em Psicologia pela UFPE, Doutora em Psicologia do Desenvolvimento pela Oxford University, Pós-doutora pela City University of New York e pela Harvard University. É Bolsista de Produtividade em Pesquisa do CNPq - Nível 1A. 